\title{
Chapter
}

\section{CELLPHONE-BASED DIAGNOSTIC DEVICES}

\section{Han-Wei Huang and Chao-Min Cheng*}

Institute of Biomedical Engineering, National Tsing Hua University, Hsinchu 30013, Taiwan 


\section{Contents}

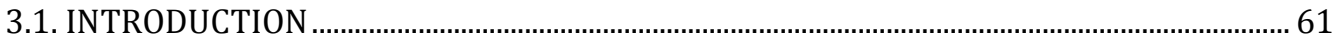

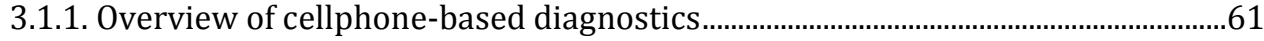

3.1.2. Benefits of cellphone devices, microfluidics, and biosensors .................................62

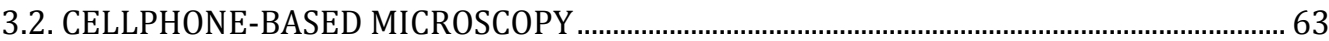

3.2.1. Cellphone-based bright-field microscopy ...............................................................63

3.2.2. Cellphone-based fluorescent microscopy ....................................................................67

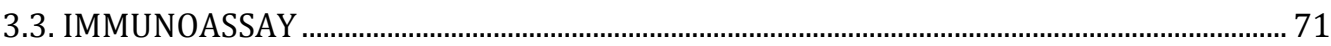

3.4. CELLPHONE-BASED SENSING.............................................................................................. 74

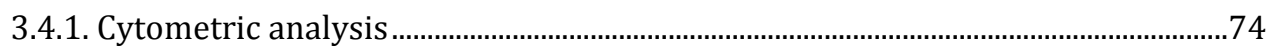

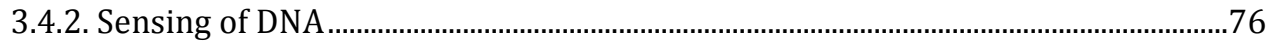

3.4.3. Sensing of proteins and other biomarkers ...................................................................79

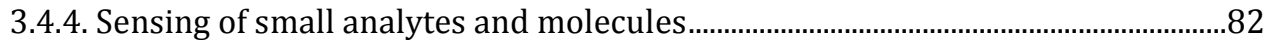

3.5. CELLPHONE-BASED DIAGNOSTICS TOOLS................................................................................ 82

3.6. DIAGNOSTIC APPLICATIONS ..................................................................................................... 83

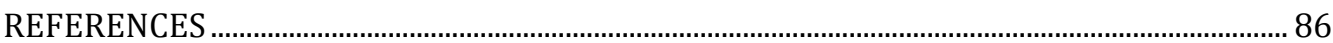




\subsection{INTRODUCTION}

\subsubsection{Overview of cellphone-based diagnostics}

Advances in information and communications technology (ICT) and complementary metal oxide semiconductor (CMOS) fabrication expand cellphone functionality in areas ranging from mere communication to entertainment to medicine. A cellphone is fundamentally equipped with a high-resolution camera, a robust microprocessor, a reliable radio frequency (RF) module for wireless connectivity, real-time geo-tagging, secure data management, and the capacity for data science interfacing (e.g., cloud computing and big data analysis) [1-2]. According to GSMA Intelligence statistics, there were as many as 4.7 billion unique global cellphone subscribers and 7.6 billion global subscriber identity module (SIM) connections in 2014 [3]. Smartphone connections will increase by 2.6 billion by 2020 [4]. There were 185 million smartphone connections as of mid-2015 in India, and this number may grow to over half a billion by 2020 [5]. In 2011, $70 \%$ of global cellphones were used in developing countries [6]. Cellphones have become ubiquitous compact electronic devices because of their affordability and ease of production.

Telemedicine aims to provide accessible, cost-effective, and easily used health care services to eliminate geographical barriers and increase access to health care systems in industrial and third-world countries [7]. Telemedicine refers to "using ICT to obtain valid information for diagnosis, treatment and prevention of disease and injuries, research and evaluation, and for the continuing education of health care providers, all in the interests of advancing the health of individuals and their communities" [7]. Presently, point-of-care testing (POCT) emphasizes the seamless integration of cellphones and diagnostics, as well as the development of reliable analytical platforms and analysis methodologies, in response to personal healthcare services [8]. Cellphonebased devices (CBDs) coupled with facile wearable devices or portable devices to monitor heart rate and perform electrocardiography, measure blood pressure, or perform ultrasound and provide ultrasound imagery are already commercially available [9-11]. Notably, cellphone cameras, which are highly suitable for optical applications, have enhanced telemedicine methodology by providing high quality optical recording and analysis and transmitting results via wireless connectivity for remote storage and additional analysis [12]. Collected information enables healthcare related organizations to easily trace, monitor, and manage diseases at a global scale, make comprehensive personal medicine plans, and even predict future trends by using a potentially massive data collection network $[7,13]$. Over the past decade, CBDs have been demonstrated in medicine, environmental analysis, and food inspection through the following applications: i) microscopy; ii) immunoassays; iii) lateral 
flow assays; iv) electrochemical sensing; v) flow cytometry; vi) surface plasmon resonance-based sensing; and, vii) colorimetric assays [1,14].

\subsubsection{Benefits of cellphone devices, microfluidics, and biosensors}

Most consumer electronic devices provide an easy route for researchers to develop new sensing applications using cellphones, scanners, and disc players on the basis of their powerful capabilities and accessibility [15-23]. Cellphones especially outweigh over others in terms of their convenience in myriad situations in mundane life. It is no wonder that researchers have pursued their use as compelling measurement devices for examination, data collection, and transmission in and from remote and resource-limited settings [24-27]. When it comes to health care exploration, cellphones may bridge existing gaps between patients and timely, affordable healthcare, especially in more remote regions. The current trend related cellphone-deprived applications is focused on result recording and interpretation, and/or transmission from test-strip style diagnostic tools or other miniature test methodologies.

Microfluidics and biosensors keep abreast the development of lab-on-chip (LOC) or point-of-care (POC) diagnostic devices that can provide lab-quality test results on the spot or for filed use. Their main contribution to cellphone-based diagnostics is that LOCs can process samples with little human intervention and reach testing outcomes at hand. These technologies have been investigated since the 1980s, but recent improvements in the availability of clinical diagnostics have spurred research for cellphone-based LOCs. Other than their widespread use for diabetes testing, biosensors have not yet reached projected analytical usage or sales estimates. The vast arrays of commercial opportunities for their use is, however, likely to inspire a substantial upswing in relevant research and commercial use pending technological breakthroughs. One of the advantages of biosensor technology is the capacity for detecting unlabeled analytes. When combined with microfluidic technologies for sample processing and reagent addition, more advanced LOCs may be realized, and research into developing such devices may grow from academic to clinical laboratory testing, and, hopefully, practical clinical applications. Molecular-based tests, decentralization of outpatient testing, and increased availability of reliable self-testing devices are providing impetus for greater miniaturization that will likely lead to a new generation of devices, commonly referred to as "chips" or lab-on-chip technology. LOC methodology refers to the use of any and all testing devices that involve any combination of multiplexed biosensors, microfluidics, or microarrays. Devices have been developed to miniaturize many kinds of diagnostic technologies, such as nucleic acid amplification and detection, critical care analytes, immunoassays, and more, however, most of the current LOC products do not perform complete sample-to-result testing. While there are some 
cellphone-based devices developed for POC applications, few LOC products have had much commercial success. Advancement in LOC technology is vital to the future success of cellphone-enabled testing, specifically if the goal is to significantly advance the state of healthcare in remote areas and engage consumers in personal, self-care programs. For full-scale commercialization of cellphone-enabled tests, LOC mechanics, accuracy, and precision, as well as economic feasibility, must be validated.

\subsection{CELLPHONE-BASED MICROSCOPY}

Cellphone cameras feature the prominent development of CBDs in optical sensing. CMOS image sensors mainly consist of a pixel sensor array (detection wavelengths: $380-1100 \mathrm{~nm}$ ) and optical filters, and are primarily used for capturing images under the visible spectrum and in the presence of ultraviolet (UV) and infrared (IR) filters [27]. Color information is processed by band-pass filters that transmit either blue, green, or red light on the pixel array; Bayer mosaic, a repetitive $2 \times 2$ grid with one red filter, two green filters, and one blue filter per four pixels, is a typical pattern of color filters in CMOS image sensors [28]. CMOS image sensors can achieve more than 40 megapixel image resolution [27].

\subsubsection{Cellphone-based bright-field microscopy}

The development of cellphone-based microscopy is intertwined with advances in lens attachment-based microscopy and lens-free holographic microscopy $[27,29]$. In 2009, Prof. Fletcher's group at UC Berkeley demonstrated the prototype of cellphone-based microscopy with a light lens attachment $(\sim 15 \mathrm{~cm}$ long) that could be used for global health applications (Figure 1A) [29]. 


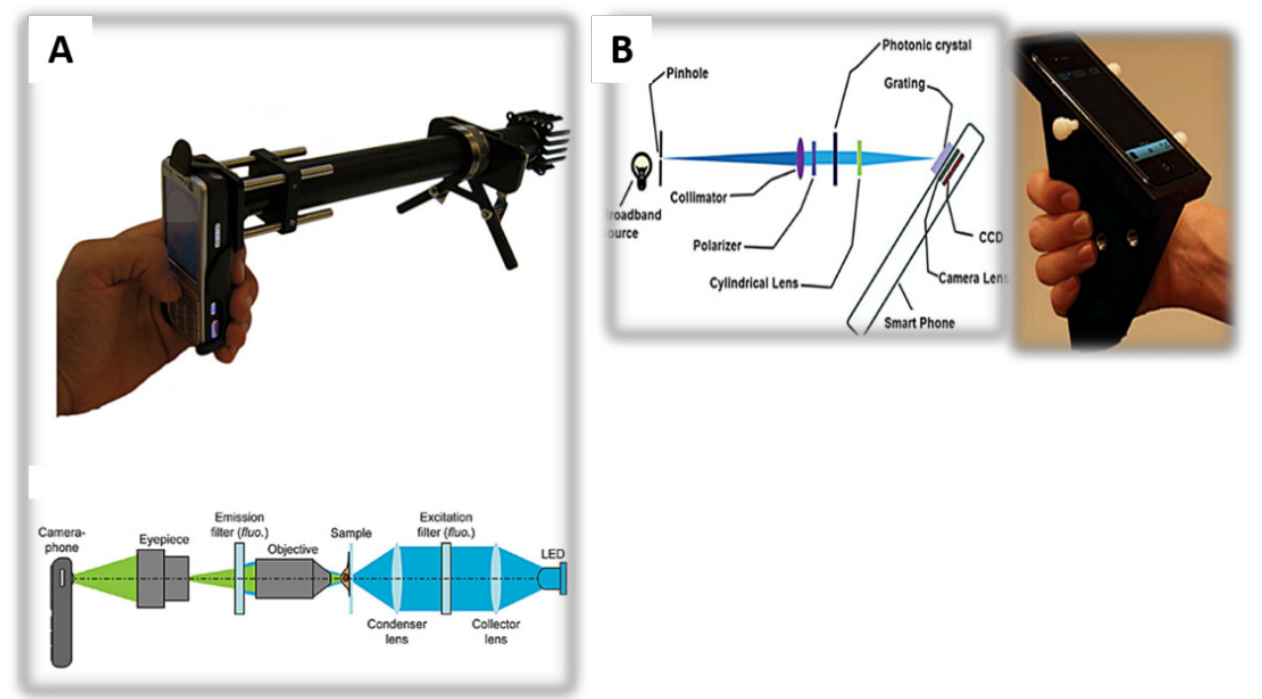

Figure 1. Bright-field microscopy on mobile phones microscopy layout schematic, prototype, and sample images

Their platform provided a spatial resolution of $\sim 1.2 \mathrm{~mm}$ over a field-of-view (FOV) of $\sim 0.025 \mathrm{~mm}^{2}$ and was available for imaging thick/thin smears of Giemsa-stained malaria-infected blood and sickle-cell anemia blood in bright-field microscopy. This system exploited the powerful computational capability of a cellphone for automatic cell counting. Since then, they have dedicated their efforts to the development of practical cellphone-based microscopy, something they call "CellScope" [30]. CellScope devices were designed for imaging granulocyte and red blood cells and performed high degrees of sensitivity and specificity in clinical Schistosoma haematobium infection diagnosis and blood-borne filarial parasites inspection (e.g., Loa loa) (Figure 2) [24,30,31]. 


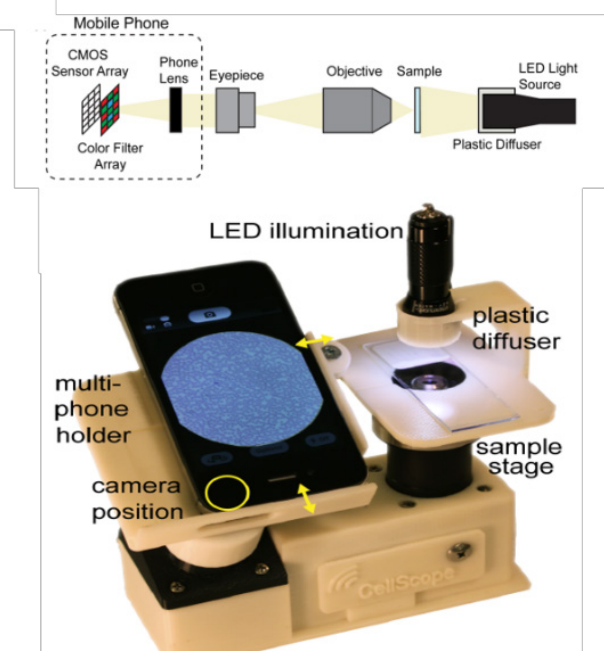

Figure 2. A Diagram of the magnifying optics and illumination added to A multi-phone mobile microscope to create a transmission light microscope

In other developments, Prof. Ozcan's group at UCLA presented the first cellphone-based lens-free holographic microscopy (without an additional lens-based attachment) in 2010 (Figure 1B) [32]. This 38 gram lens-free platform, composed of battery, light-emitting diodes (LEDs), and an aperture $(100 \mu \mathrm{m})$, could be mounted on the front of a cellphone camera as an optical sensor without additional optical components. Emitted incoherent LED light passed through the aperture and scattered and refracted from each micro-sample after traveling in air a distance of $\sim 4 \mathrm{~cm}$ to coherently interfere with background light. Consequently, holographic images were formed on the sensors of a cellphone according to dimensions, 3D morphologies, sub-cellular elements, and refractive indexes of samples. Notably, its large aperture enhanced light transmission by several orders of magnitude and decreased misalignment error. Spatial resolution of this system with different CMOS sensors ranged from $<1-2.2 \mu \mathrm{m}$. This system successfully imaged micro-particles, red blood cells, white blood cells, platelets, and a waterborne parasite (Giardia lamblia). In addition, this group proposed the technology of lens-free incoherent holograpy to reach a large FOV over high spatial resolution [33]. This incoherent holographic microscope $(\sim 46 \mathrm{~g})$ had dimensions of approximately $4.2 \times 4.2 \times 5.8 \mathrm{~cm}$ and offered spatial resolutions of 1-2.2 $\mu \mathrm{m}$ over a FOV of $\sim 24 \mathrm{~mm}^{2}$. Superior imaging results in this system were associated with suppressing coherent speckle noise and inhibiting undesired multiple reflection interference effects on the detected holograms. Based on these accumulated successes, CMOS, chip-based, lens-free holographic microscopy has advanced to wide-field super-resolution microscopes, or gigapixel nanoscopes, which were successfully used to analyze 
sperm, red blood cells, a malaria parasite (Plasmodium falciparum), nanotube measurement, and even perform a Papanicolaou (Pap) test [34-38]. In additional research, a cellphone camera coupled with a fiber-optic array exhibited unique cellphone-based computational microscopy (Contact Scope) [39]. Contact Scope highlighted the capability of multi-frame imaging resulting from subtle image scanning (1-2 degrees for single scanning) and a special shift-and-add algorithm installed on a cellphone for merging images.

Taking a more simplistic approach, one recent manuscript provides the details on how a cellphone-based 350x microscope or visible-light spectrometer could be built using a ball lens and a collimating tube [40]. The ball lens described was used to image Wright-Giemsa-stained blood smears and unstained peripheral blood smears that were automatically analyzed using a CellC program, and the spectrometer was capable of measuring material transmission spectrums. Ball lens-based microscopy has also been applied in soil-transmitted helminth infection analysis [41], but such systems are not capable of providing a high spatial resolution over a large FOV. Cellphone-based microscopy with a reversed camera lens significantly ameliorated this disadvantage by eliminating optical ball lens system aberrations [42]. In addition to designing cellphone-based microscopy systems with traditional optical lenses, water and poly(dimethylsiloxane) (PDMS) droplets might be employed as alternative lenses [43,44]. Prof. Prakash and his group successfully completed an exceptionally novel effort to create an extremely low-cost and compact microscope by developing an origami-based foldscope that, coupled with a cellphone, could be used for parasite disease investigations (Figure 3) [45]. 

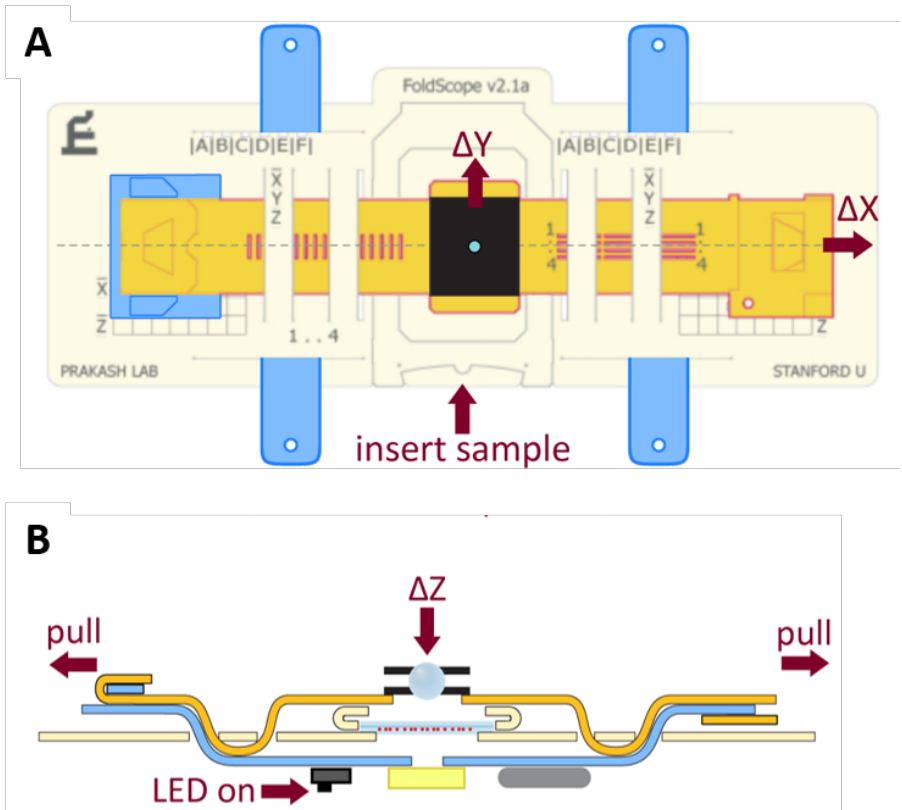

Figure 3. Schematic of an assembled Foldscope illustrating panning, and cross-sectional view illustrating flexure-based focusing

This foldscope was assembled from a flat sheet of paper in less than $10 \mathrm{~min}$ and was capable of greater than 2,000× magnification with submicron resolution, weighed less than $8.8 \mathrm{~g}$ (equal to the weight of two nickels), could be loaded in a pocket $\left(70 \times 20 \times 2 \mathrm{~mm}^{3}\right)$, required no external power, and remained functional even after it was dropped from a 3-story building or stepped on. While cellphones have been successfully used for a variety of diagnostics, it is notably impressive that they have also been used as ocular imaging devices [46,47]. Corneal CellScope devices, for instance, have been used for retinal examination, corneal abrasions, and ulcers diagnosis in clinical studies.

\subsubsection{Cellphone-based fluorescent microscopy}

Beyond the array of bright-field microscopy applications that cellphones have been found suitable for, using them for fluorescence microscopy provided pivotal impetus for research focus on cellphone-based diagnostics. Fluorescent probes / assays have long allowed researchers to specifically track bioindicators and track biomarker levels, especially in extremely low concentration. Pioneering work in cellphone-based microscopy (Figure 1A) also demonstrated the capacity to perform M. tuberculosis-infected sputum 
diagnosis with a fluorescence assay [29]. Nevertheless, associated low FOV impeded the observation for relatively large volumes of samples (i.e., $>0.1 \mathrm{~mL}$ ). Researchers have since proposed a more compact optical attachment $(3.5 \times 5.5 \times 2.4 \mathrm{~cm})$ that achieves a FOV of $\sim 81 \mathrm{~mm}^{2}$ with a spatial resolution of $\sim 20 \mu \mathrm{m}[48]$ (Figure 4).

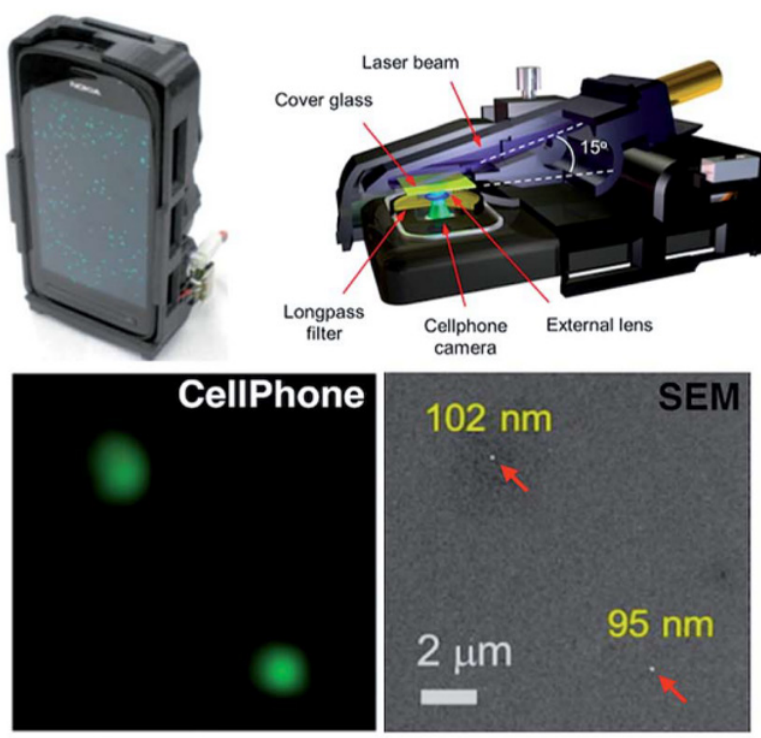

Figure 4. Schematic diagram and prototype of the designed optical attachment for wide-field fluorescent imaging on a cell-phone. And Cell phone-based fluorescence imaging of individual NPs and viruses.

With post-processing image software, spatial resolution of captured fluorescent images can be lowered to $\sim 10 \mu \mathrm{m}$. This platform allowed blood, urine, sputum, or water analysis, including the examination of white blood cells from whole blood samples and Giardia Lamblia cysts inspection from water samples. Additionally, CellScope devices can be adopted into a fluorescent imaging system for clinical tuberculosis (TB) diagnosis [49-51]. Recently, a miniaturized fluorescence microscope coupled with a CMOS sensor system has been applied to sophisticated neuroscience research [52]. This device successfully measured cerebellar microcirculation across different locomotor behaviors in active mice and simultaneously tracked more than 200 of $\mathrm{Ca}^{2+}$ spiking Purkinje neurons across nine cerebellar microzones (Figure 5). 
A

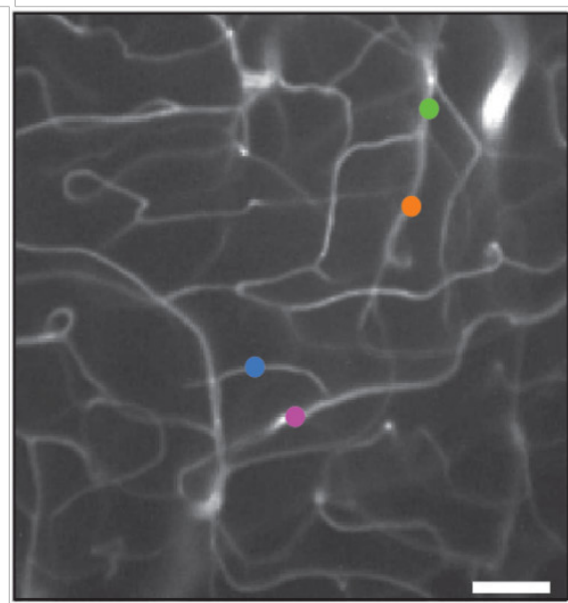

\section{B}

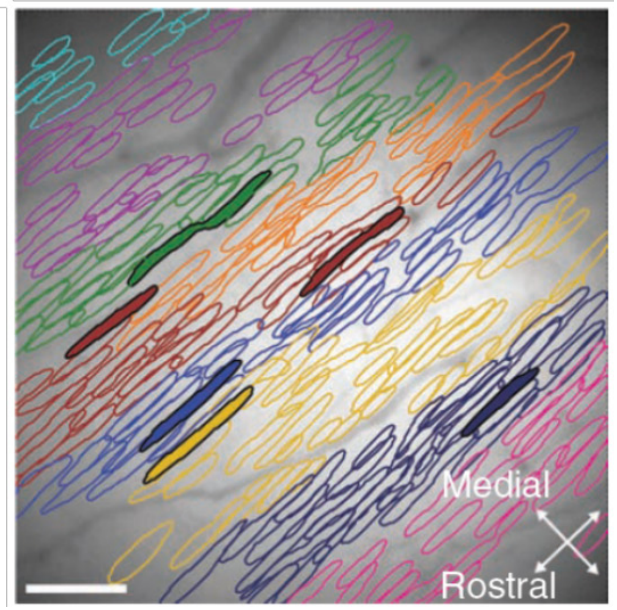

Figure 5. Cerebellar microcirculatory dynamics in freely behaving mice and Purkinje neurons' $\mathrm{Ca}^{2+}$ spiking dynamics during motor behavior

With the rise of microfluidic technologies, cellphone-based fluorescent microscopy continues to keep pace, from a conjoined research perspective, with microfluidic application developments [53]. In addition to bacteria and parasite detection, hand-held cellphone-based fluorescent devices have demonstrated the capacity to image objects at nanoscale, i.e., viruses and single nanoparticles in microfluidic platforms (Figure 6) [27]. 

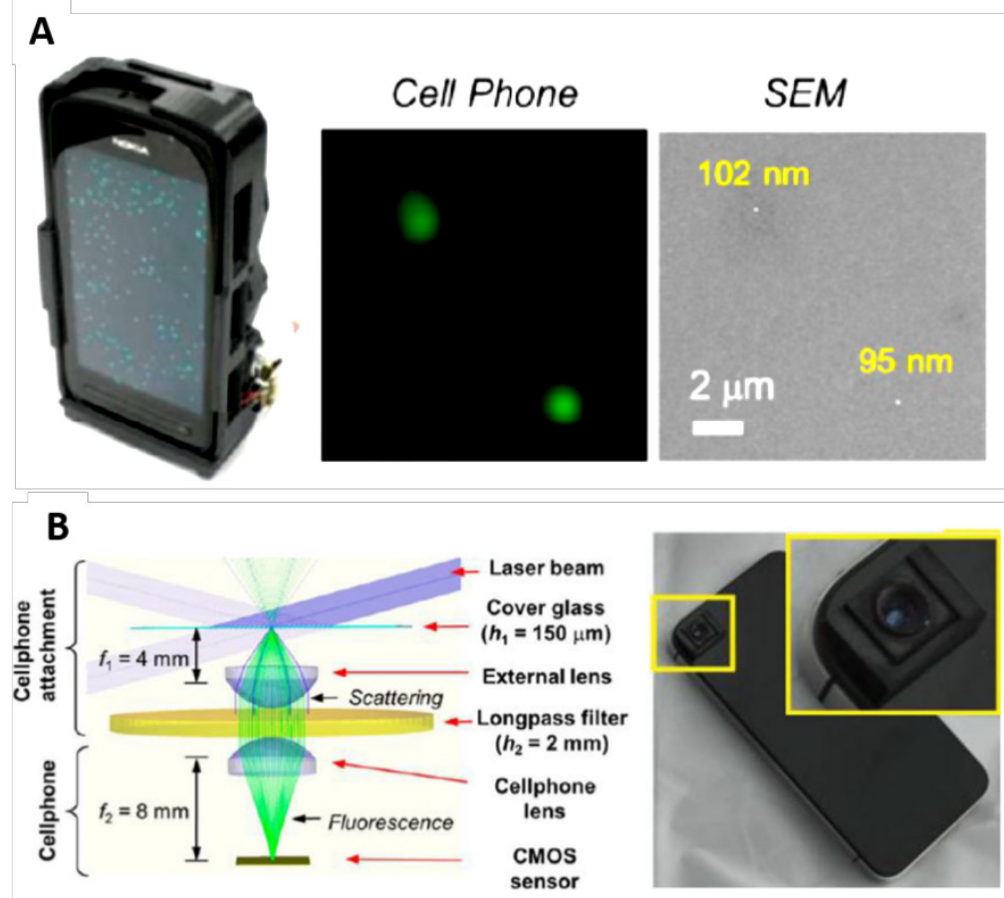

Figure 6. Photographs and schematics of our cellphone-based fluorescence microscope

For simple cell behavior research, a USB microscope-based microfluidic chemotaxis analysis system was designed to investigate cell migration in microfluidic devices [54]. Considering a cost-effective way to analyze biological information, a quantum dot barcode cellphone-based device has been developed to diagnose virus-infected patients (Figure 7) [55]. 

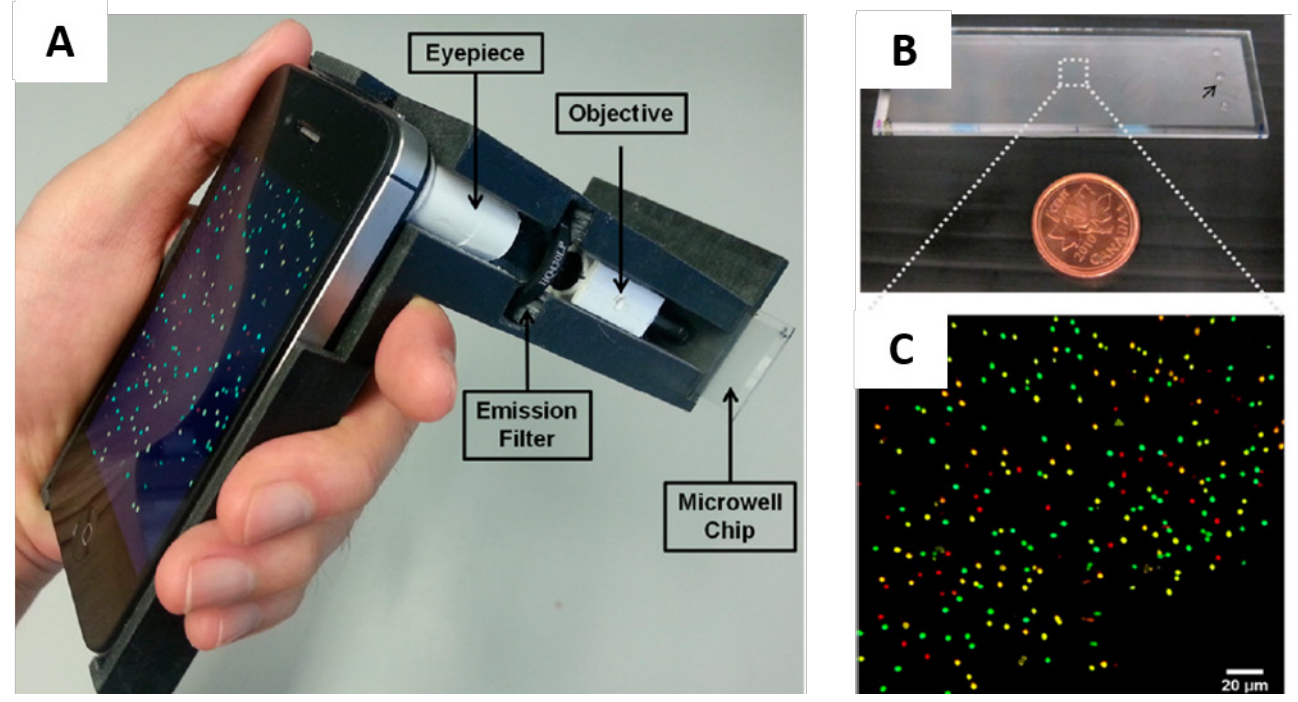

Figure 7. Overview of the smartphone device utilizing QD barcodes that captures the image of four different QD barcodes arrayed on the surface of the chip and the image of the smartphone device.

This system used DNA probes modified on the surface of microbeads to capture target DNA sequences produced by isothermal amplification. Quantum dots was then designed to indicate the detection outcomes. The advantage of this system was capable of simultaneously analyzing multiple infectious pathogens (e.g., HIV, hepatitis B or C, and influenza viruses) in less than one hour.

\subsection{IMMUNOASSAY}

Since the creation of the radioimmunoassay (RIA) in 1950s, immunoassay applications have been employed in laboratory or analytical settings (e.g., vaccine efficacy screening) [56]. In this process, antibodies recognize antigen epitopes via non-covalent binding, which provides immunoassays with high degrees of selectivity and superior sensitivity. In addition, immunoassays easily adapt to arrays of reporter systems when employing antibodies with different chemical tags, such as fluorescence and chemiluminescence indicators or enzymes for colorimetric indication systems [57]. Among the immunoassays currently being explored and developed, sandwich assays, competitive assays, and antigen down assays are common approaches. The powerful analytical capabilities of such assays and the high degree of approach flexibility has partly driven the development of diverse CBDs for biochemical detection. 
Cellphone cameras are frequently high enough in quality that they can be used for a variety of scientific assays that would otherwise require costly equipment, such as a spectrophotometric plate reader, commonly used for conventional immunoassays. This use had been successfully demonstrated to detect C-reactive protein (CRP) via ELISA [58]. The LODs of CRP analysis recorded by a cellphone and a spectrophotometric plate reader were $0.026 \pm 0.002 \mu \mathrm{g} \mathrm{mL}^{-1}$ and $0.007 \pm 0.001 \mu \mathrm{g} \mathrm{mL}^{-1}$, respectively. Note that CRP level over $3 \mu \mathrm{g} \mathrm{mL}-1$ indicates high cardiovascular disease (CVD) risk. This simple method resulted in qualified performance in CVD risk assessment and comparable analytical outcomes to standard instrumentation. Moreover, by adding a dark hood and a base holder assembly, direct ELISA with HRP for CRP analysis reached a dynamic range, limit of quantitation (LOQ), $\mathrm{EC}_{50}$, LOD of $0.114-7.300 \mathrm{ng} \mathrm{mL}^{-1}, \quad 0.114 \mathrm{ng} \mathrm{mL}^{-1}, \quad 0.198 \mathrm{ng} \mathrm{mL}^{-1}$, and $0.973 \mathrm{ng} \mathrm{mL}^{-1}$, respectively [59]. With advances in microfluidics, CMD design development has also advanced to record the variety of immunoassay results capable with microfluidic devices. This has been demonstrated via analysis of human Immunoglobulin G (IgG) on chips via a process that analyzed signal intensities of gold nanoparticles, in combination with silver staining, to determine proportional IgG concentrations [60]. Moreover, CMD design using microchip ELISA has been used to detect ovarian cancer marker [human epididymis protein 4 (HE4)], a process that underscores the potential for CMD-based microfluidic devices for POC diagnostics [61]. Following a set of operation steps (including running an analytically based cellphone application), this chip demonstrated a sensitivity of $89.5 \%$ and a specificity of $90 \%$ for clinical HE4 detection. CMDs have also been used for prostate cancer diagnosis. In this research, a portable cellphone-based colorimetric and fluorescence system was used to quantify prostate specific antigen (PSA) (Figure 8A) [62].
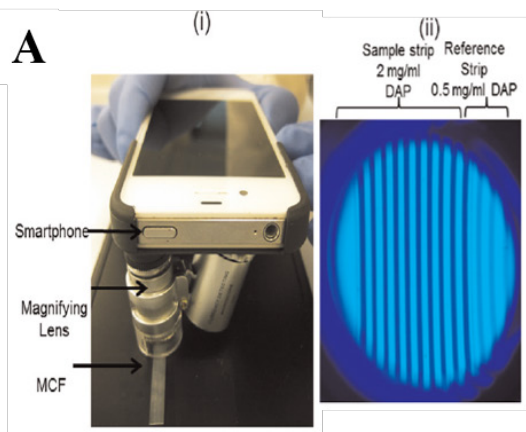

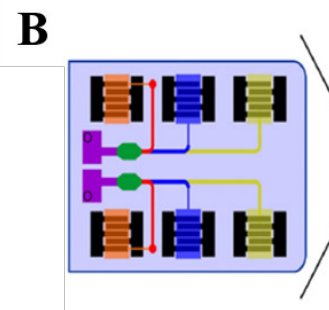

ELISA-on-a-Chip
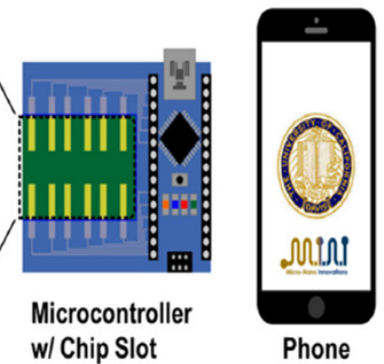

Phone

Figure 8. (A) A micro capillary film (MCF) platform for prostate specific antigen (PSA) detection. i)the setting of a MCFphone device; and, ii) A MCFphone colorimetric image of sample and are reference strips coated with 2,3-diaminophenazine (DAP) and $o$-phenylenediamine dihydrochloride. (B) Diagram of a plug-and-play microfluidic ELISA chip designed to analyze the presence of BDE-47

$(2,20,4,40$-tetrabromodiphenyl ether). 
This system was integrated with a fluoropolymer microfluidic device to implement an ELISA-based PSA analytical procedure specifically in whole blood. Notably, the process took only $13 \mathrm{~min}$ for colorimetric analysis or 22 min for fluorescence analysis. Further advancements in the use of CMDs have employed microfluidic-like glass-based capillary arrays in combination with a compact cellphone attachment to quantify Escherichia coli (E. coli) levels in liquid samples [63]. This system leveraged a type of quantum dot (emission at $625 \mathrm{~nm}$ ) to report detection results, and demonstrated an LOD of $\sim 5-10 \mathrm{cfu} \mathrm{mL}^{-1}$ in buffer solutions. For some cases, microfluidic-based immunoassays encounter long processing time for blocking treatments in the presence of complex device patterns. A lateral hydrogel-deprived chip for a barcode sandwich immunoassay presented a hepatitis C viral (HCV) in $1 \mathrm{~h}$ using low power electrophoresis [64]. In an effort to manage global health or understand causes of diseases thoroughly, the influences of environmental contaminants or food hazards must not be neglected. Severe air pollution, for example, is linked to respiratory tract infections and chronic obstructive pulmonary disease, and contaminated food and water has often induced diarrheal diseases [65]. A plug-and-play microfluidic ELISA chip was designed to analyze the presence of BDE-47 (2,20,4,40-tetrabromodiphenyl ether) [66]. Studies showed that long-term exposure to BDE-47, a common type of polybrominated diphenyl ethers (PBDEs) as flame retardant in consumer products, significantly deteriorated cognitive function and motor behavior in infants (Figure 8B) [67]. This device design employed an easily used USBinterface that could be attached to a mobile platform to control the analytical procedure without additional laborious effort, and with a linear range of $10^{-3}-10^{-4} \mu \mathrm{g} \mathrm{mL}{ }^{-1}$.

The typical lateral flow assay (LFA) format first appeared in 1988; its development is credited to the Unipath laboratory [68]. LFA-related products have blossomed in diverse biochemical aspects (e.g., home pregnancy test, infectious disease test strips) and has always kept a keen focus on the advantages of light weight, facile manipulation, short testing periods, and low cost, as compared to traditional ELISA. In response to computer screen photo-assisted technique (CSPT), cellphones have been considered an available substitute to conventional complex settings [69]. An $N$-terminal proBNP (NT'”-proBNP) test coupled with a cellphone was capable of determining NT-proBNP concentration by high dynamic range (HDR) image acquisition [69]. For thyroid stimulating hormone (TSH) diagnosis, conventional LFA rarely achieve the detection criteria for hyperthyroidism analysis (TSH levels $<0.4 \mathrm{mIU} \mathrm{L}^{-1}$ ) [70]. One cellphone-based TSH diagnostic platform focused on the influence of Mie scatter and substantially decreased light scatter associated with nitrocellulose membrane use; this approach significantly improved sensitivity and reproducibility and lowered the LOD to $0.31 \mathrm{mIU} \mathrm{L}^{-1}[70]$. 


\subsection{CELLPHONE-BASED SENSING}

The advantages of cellphone-based sensing go beyond microscopy. The capacity to capture high quality color images and video provides opportunities for additional imaging analysis that is valuable for POC settings. Cellphone-based sensing platforms can detect and analyze a wide range of inorganic and organic targets, including cells. CMDs, especially those that work in tandem with lab-on-a-chip technologies facilitate cost-effective, field-portable, and rapid sample processing to achieve high specificity and sensitivity including the sensing of biomarkers (Figure 9) [71,72].

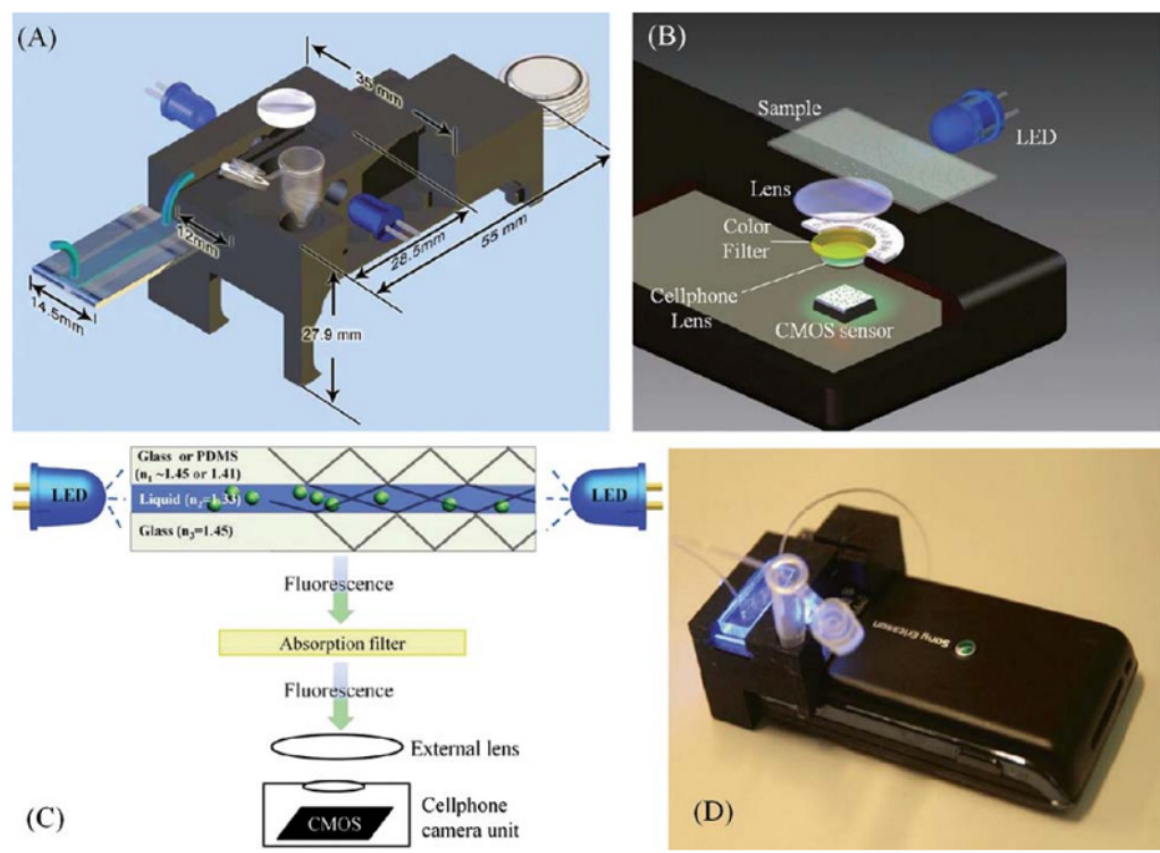

Figure 9. Various schematic diagrams of the designed optical attachment for optofluidic fluorescent imaging cytometry on a cell phone are illustrated. The picture of the optofluidic fluorescent imaging cytometer on a cell phone.

\subsubsection{Cytometric analysis}

Cellphone-based imaging and counting of microorganisms, such as E. coli and Giardia lamblia have also been demonstrated within the food and health safety $[26,32,73]$. In previous studies, custom designed disposable water sample cassettes were used to collect fluorescently labeled Giardia cysts (e.g., 10-20 mL) (Figure 10) [26]. 

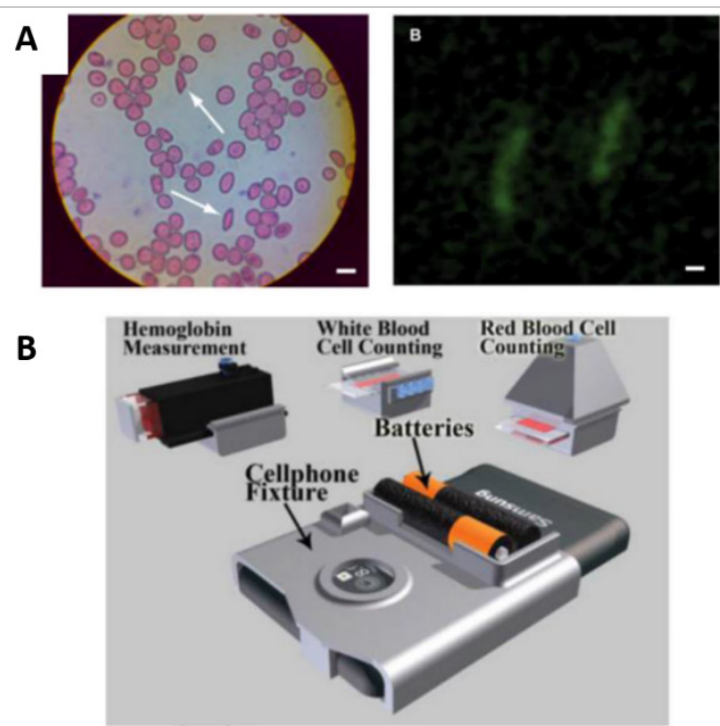

Figure 10. Mobile phone based platform for automatic detection and counting of Giardia cysts using machine learning that adapted by permission of The Royal Society of Chemistry.

Another advantage of cellphone-based combination studies is the detection and quantification of individual cells or microorganisms for specific and sensitive detection of many pathogens in various fluids. D'Ambrosio et al. recently produced a compact bright-field video microscope using a cellphone that could capture the "wriggling" motion of Loa loa (L. loa) microfilariae (mf) parasites $(\sim 200 \mu \mathrm{m}$ in length) in whole blood [24].Compact and cost-effective flow cytometry on a cellphone for rapid blood analysis has also been implemented [74,75]. In a recent cytometry approaches, the measurement components of leukocyte counts (using fluorescence), erythrocyte counts (using bright-field), and hemoglobin density (based on absorbance quantification) have been added to the growing list of cellphone-based diagnostic devices [75]. In addition to these, cellphone based imaging of fluorescent single nanoparticles and viruses [human cytomegalovirus (HCMV)] has also been recently reported [75].

Indirect cytometric analysis on cellphones has been illustrated using different assays and optical sensing mechanisms. Park et al. detected Salmonella using Mie scattering from immune-agglutinated submicron particles on multichannel paper microfluidics [76,77]. Further, Kadlec et al. used a cellphone based system, an iPhoto-meter, to evaluate antimicrobial resistance of by quantifying the growth of E. coli in urinary tract infection [78] (Figure 11). 


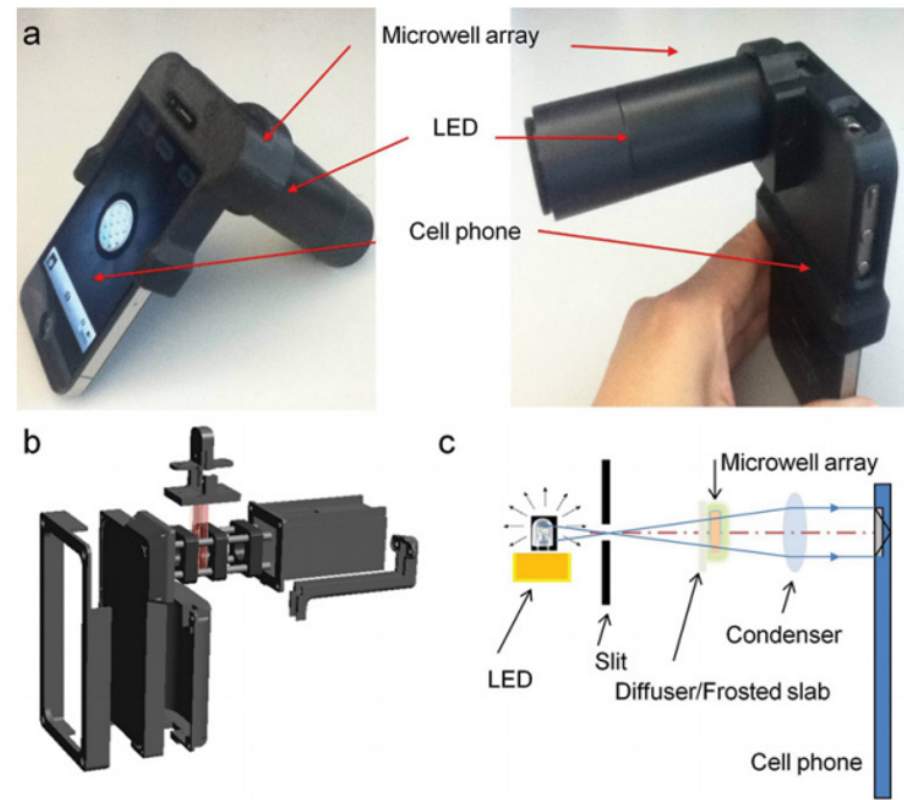

Figure 11. Photographs of the cell phone-based microphotometric system (iPhotometer) for rapid antimicrobial susceptibility testing at the POC

\subsubsection{Sensing of DNA}

From the dissertation above, DNA biomarkers can be recognized through cellphones using different sensing mechanisms. In order to detect the low copy number of target DNA molecules, DNA amplification is a key point to consider in cellphone sensing platforms to strengthen the signal intensity. These approaches include polymerase chain reaction (PCR) and loop-mediated isothermal amplification (LAMP). Promising studies have been reported in this field recently.

Examples of DNA biomarker sensing include the following:

1. Lee et al. reported a cellphone-based portable PCR device for the amplification and detection of hepatitis B virus (HBV) plasmid that eliminated the need for thermal cycling control [79].

2. Selck etal. demonstrated a cellphone-based fluorescence imaging device for quantifying digital reverse-transcription loop mediated amplification

(RT-LAMP) on a chip to detect RNA molecules of human immunodeficiency virus (Figure 12) [80]. The authors demonstrated fluorescence readout and dLAMP validity under different lighting conditions and reaction temperatures. 

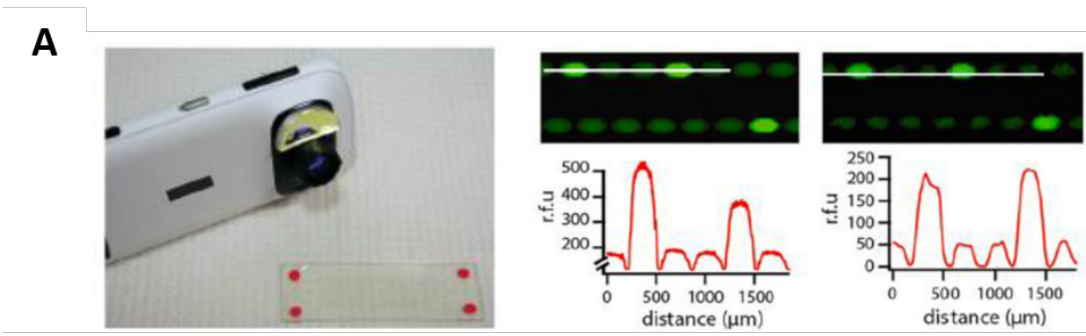

B

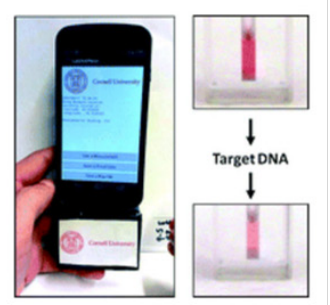

Figure 12. Sensing of DNA biomarkers with mobile phone devices

DNA molecules can also be detected using cellphone devices without using amplification steps. Examples of this include the following:

1. Zhang et al. developed a cellphone-based DNA microarray reader for capturing a transmission image under white illumination of LED [81]. The microarray slide worked with multiplexed ssDNA probes, and enhanced target DNA sequence by magnetic bead-attached ssDNA probes.

2. Huang and Ugaz developed a label-free DNA detection method based on the electrochemical dissolution activity of chromium and monitored by a cellphone (Figure 13) [82]. 
A
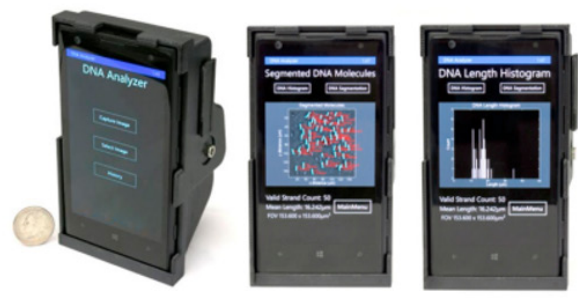

C

Step 1. Compress Step 2. Seal

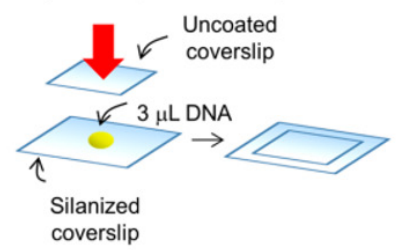

B

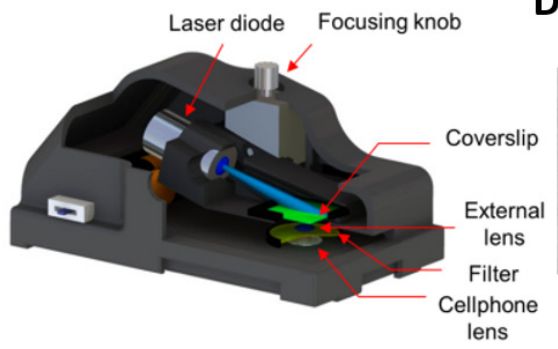

D
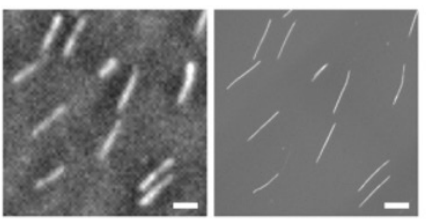

Figure 13. Imaging and sizing of single DNA molecules on a mobile phone

3. Veigas et al. demonstrated a paper-based gold nanoparticle (Au NP) colorimetric assay using a cellphone to detect mycobacterium TB complex DNA [83]. This approach relied on salt-induced color change as Au NPs were functionalized with single-stranded probe DNA. Similar research using smartphone-based technology in combination with microfluidic chips has been done by the Mancuso group. They detected Kaposi's sarcoma-associated herpesvirus (KSHV) DNA concentrations with an Au NP-based colorimetric assay [84].

4. Noor and Krull reported on a DNA diagnostic platform (Figure 14) using a paper-based fluorescence resonance energy transfer (FRET) sensor and an iPhone or iPad for fluorescence detection [85]. 


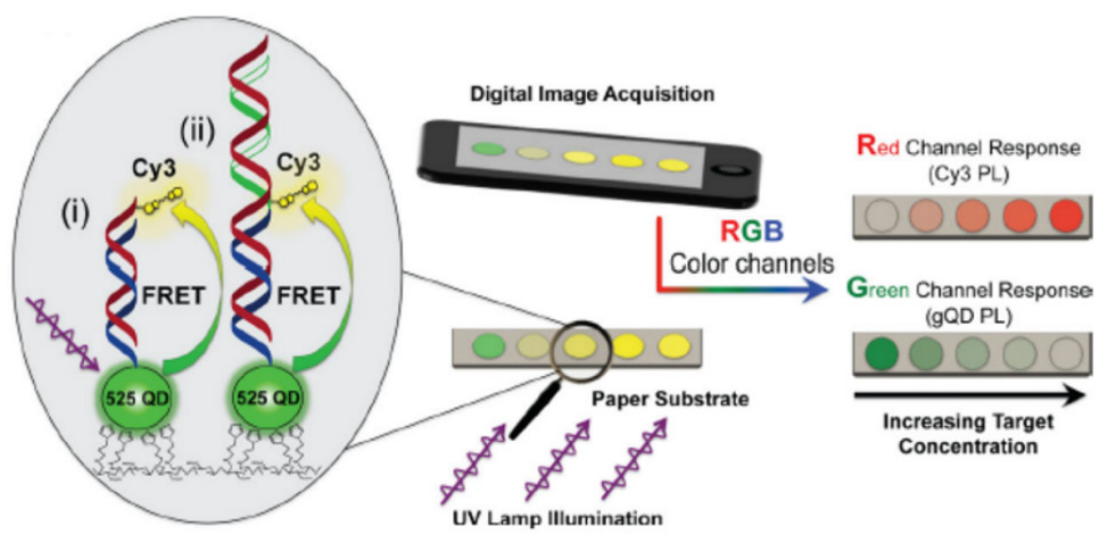

Figure 14. Cellphone assisted DNA diagnostic platform by incorporating a paper based FRET sensor

\subsubsection{Sensing of proteins and other biomarkers}

Small biological molecules and proteins can be detected by cellphone diagnostic platforms as biomarkers, such as antibody based recognition assays. ELISA is a common biochemical assay to generate colorimetric or fluorescent signals using microfluidic chips that leverage the sandwich structure of immobilized capturing antibody, targeting antigen/biomarker, and enzyme-conjugated secondary antibodies. In some well-known studies, a special cellphone attachment was developed to image a 96-well plate with constant sensitivity (Figure 15) [86].
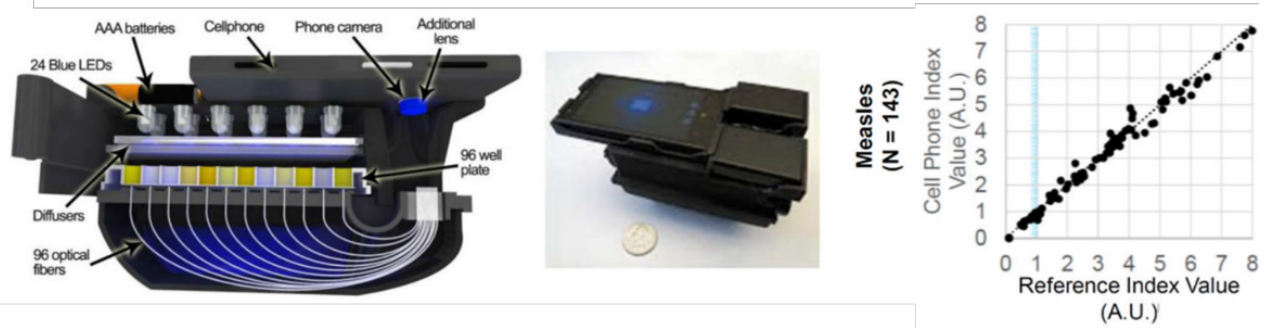

Figure 15. Sensing of protein and other biomarkers with mobile phone devices. Cellphone based ELISA reader for POC applications and performance comparison with a conventional benchtop plate reader. 
Additional examples of sensing proteins and other biomarkers include the following:

1. Vashist et al. also demonstrated a cellphone-based 96-well ELISA reader that could hold both the plate and cellphone [59].

2. Chen et al. also developed a smart phone-interfaced microfluidic ELISA platform to detect a food contaminant [87].

3. Wang et al. reported a diagnostic device that combined a cellphone fluorescence reader with a droplet-based ELISA assay to analyze HIV p24 capsid protein [88].

Another advantage of cellphone assays is that they can control microfluidic performance by adjusting electrodes in microfluidic pumps using voltage input control from the cellphone. In a well-known example of this, LFA tests including those for TB, malaria, and HIV have been demonstrated using an android phone- or iPhone-based rapid-diagnostic-test (RDT) reader [89] (Figure 16).
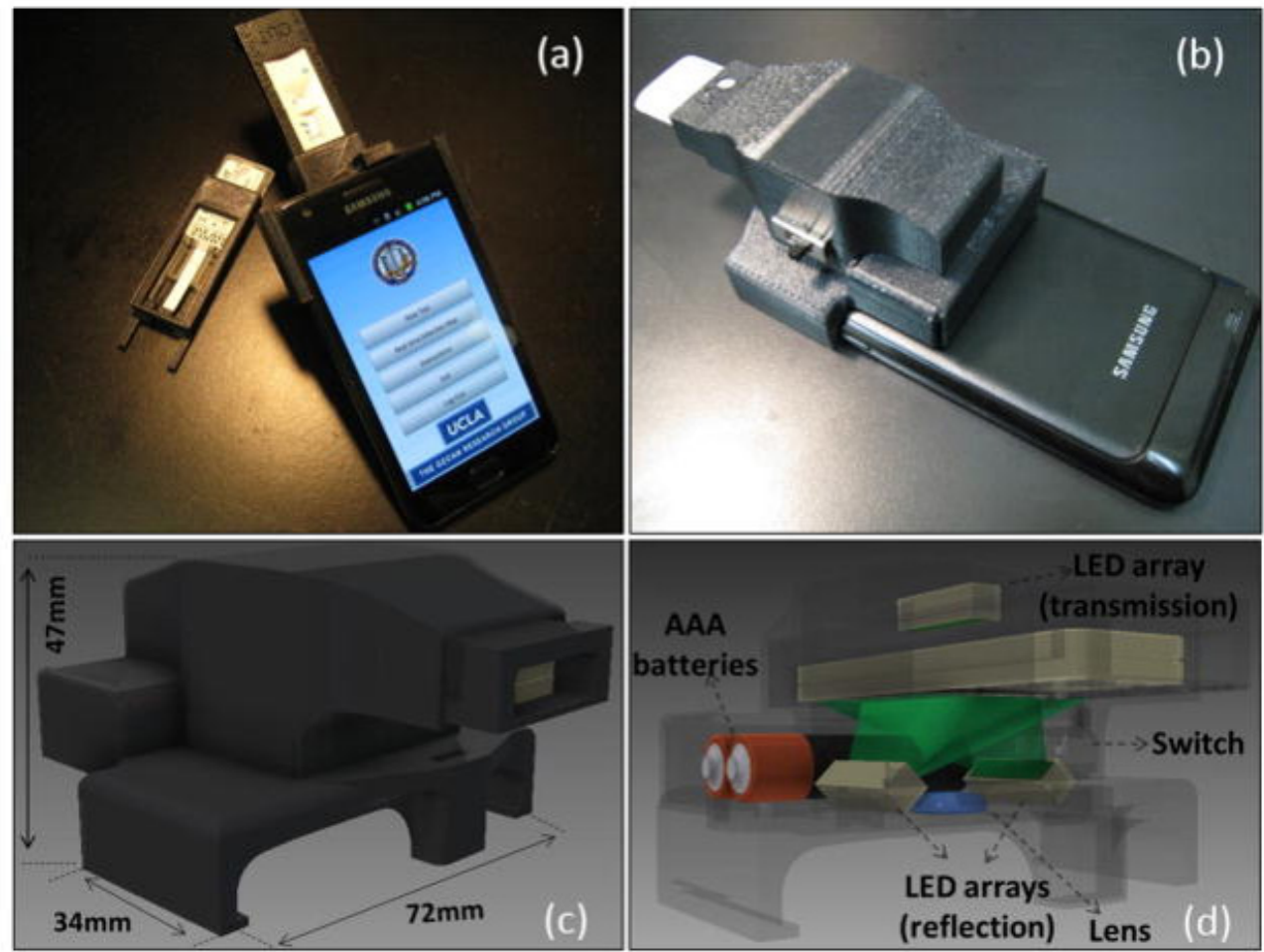

Figure 16. Different views of our smart RDT reader prototype installed on an Android phone (Samsung Galaxy S II). Schematic diagrams of the designed optical RDT reader attachment are shown. It utilizes three LED arrays with diffusers to ensure uniform illumination of the tests which are loaded to the attachment with customized trays. 
Fluorescent LFA enhances sensitivity and dynamic range. It has been used to diagnose multibacillary leprosy and food contamination induced by aflatoxin and combined specific immunochromatographic strips with cellphone diagnostic devices [90,91]. Using different smartphone accessories and test strips, one can monitor $\mathrm{pH}$ in sweat or cholesterol in saliva and vitamin D levels in blood samples [92-93].

The conjugation of paper based devices with cellphone imaging systems has many potential applications and can be engineered into complex forms to lead complicated biomarker detection assays. In addition, there is a variety of optical sensing and measurement techniques for biomarker detection using cellphone platforms. In some recent and well-known examples, Martinez et al. demonstrated the quantification of paper-based microfluidic assays using camera phones as a proof of concept (Figure 17) [94].

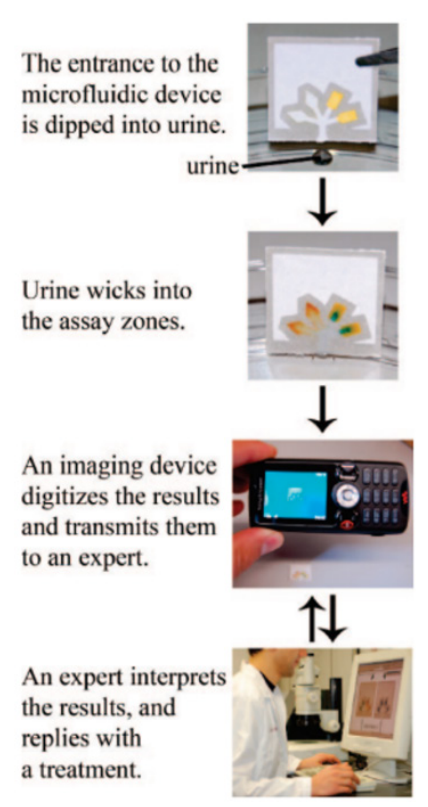

Figure 17. General strategy for performing inexpensive bioassays in remote locations and for exchanging the results of the tests with offsite technicians

Gallegos et al. used a cellphone camera as a spectrometer for label-free biodetection on a photonic crystal [95], wherein sensing of a protein monolayer adsorbed onto the photonic crystal was successfully demonstrated. In this approach, an external broadband light source was used to provide light to the system via a pinhole that dispersed the wavelength components on the cellphone cameras CMOS sensor array. 


\subsubsection{Sensing of small analytes and molecules}

Small analytes and molecules have also been detected using cellphone platforms as valuable analytic measurement tools [96-99]. The following are some examples of this:

1. Sicard et al. carried out colorimetric tests on paper-based sensors to sense organophosphate pesticides [100]. The cellphone-based imaging system and processing algorithms made analyte quantification possible under different conditions of illumination.

2. Colorimetric sensing of mercury is very important for water quality and environmental monitoring applications. El Kaoutit et al. advanced colorimetric substrates for detection of mercury(II) $\left(\mathrm{Hg}^{2+}\right)$ ions in water samples [101]. These substrates was detected for $\mathrm{Hg}^{2+}$ quantification in the millimolar to nanomolar range with cellphone imaging system, but there were still some variability regarding user operation limits and illumination effects.

3. Sumriddetchkajorn et al. combined a cellphone system with a rapid colorimetric test to monitor and quantify chlorine in water samples [102].

4. Employing the principle cellphone use to quantify colorimetric results of a paper-based test. Lopez-Ruiz et al. demonstrated the simultaneous measurement of $\mathrm{pH}$ and nitrite concentration in water samples. From these studies above, cellphone-based sensing platform was utilized to create a spatiotemporal map of mercury contamination for water quality monitoring applications [103].

\subsection{CELLPHONE-BASED DIAGNOSTICS TOOLS}

Cellphone based imaging and sensing platforms are valuable tools for POC diagnostics because of their field-portability, cost-effectiveness, and ease of use. As mentioned above, cellphones-based devices can sense biomarkers, provide counting capabilities, and imaging of cells / microorganisms for environmental monitoring and food safety, but may also be used for a variety of clinical applications [79,81,94,104]. The compatibility of cellphone platforms and various RDT formats clearly demonstrates successful quantitative and real-time analysis of immunochromatographic RDTs [89]. These approaches can also be used to assess RDT results under low antigen concentrations and provide spatiotemporal mapping of tests results that are useful for epidemiology.

Moreover, development of multiple biomarker POC diagnostic assays with resource-limited settings is a key focus point for mobile diagnostics. Ming et al. have shown that cellphone-based fluorescence imaging can be used for 
multiplexed detection of DNA analysis that corresponds to the detection of several infectious pathogens [55]. They combined a cellphone-based microscope using quantum dots and DNA sequence conjugation to create a device that could detect HIV, HBV and hepatitis C virus (HCV) in a single test. Note, the LOD of this system has been established as 1000 copies $\mathrm{mL}^{-1}$. In other research, Laksanasopin etal. created a low power consumption smartphone attachment capable of triplexed ELISA assays specific to HIV and syphilis $[25,105]$. Further, cellphone-based optical devices have also been used for early diagnosis of human eye cataracts [106] without expensive equipment or highly trained medical staff. This approach relied on forward scattering and user interaction, even allowing for self-evaluation, and responded in real-time. To complete analysis, reconstructed opacity and attenuation maps of the user's eye could be used to determine cataract severity.

Emerging wearable technology is a recently popular area of diagnostic tool research. Google Glass is among the developments that can provide new imaging and sensing functions for POC diagnostics; it employs a hands-free and voice-activated interface. Google Glass has been used for digital quantification of RDTs and demonstrated labeling of one or more RDTs by quick response (QR) code identifiers using the built-in camera of the Glass [107]. QR-tagged images were captured by the Glass, analytical algorithms were run on remote servers, and results were returned and displayed rapidly on the Glass screen. This approach has been used in experiments to qualify HIV and quantify PSA.

\subsection{DIAGNOSTIC APPLICATIONS}

Intensified research has focused on the development of advanced smartphone-based devices and applications (SBDAs) that offer low cost and personalized mHealthcare. Current smartphones are increasingly loaded with a variety of sensors, including cameras, light detectors, fingerprinting and proximity sensors. SBDAs offer great potential for delivering mHealthcare to remote, resource-limit, private, and public settings (Figure 18). 


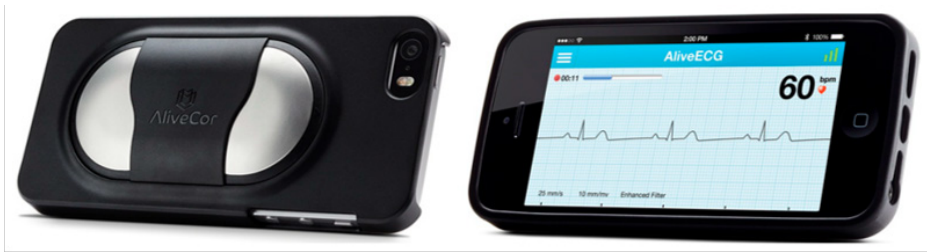

(a)

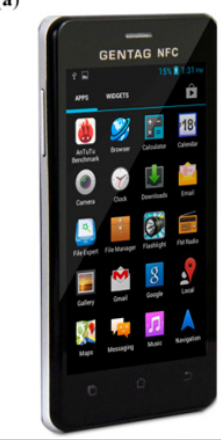

(b)

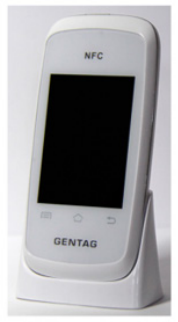

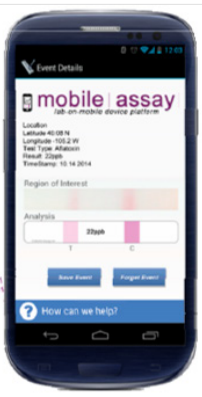

Figure 18. AliveCor Heart Monitor. NFC smart cell phone and NFC SensorLinker by GENTAG. The mobile diagnostic reader (mReader ${ }^{\mathrm{TM}}$ ) by Mobile Assay.

In telemedicine, real-time diagnostics with appropriate information provided by smart devices can be stored in a secure central server for access by healthcare professionals in distant locations. This feature is crucial for the monitoring and effective management of epidemics and individual emergency cases [108]. Over $94 \%$ of the world population, about 6.8 billion people, are cellphone subscribers, and around 2.7 billion subscribers use the internet [109]. Cellphone subscriptions might reach 8.5 billion by the end of 2016 with $70 \%$ of smartphone users coming from developing countries [110]. This fast growth along with evolving technological features and cost reduction has vastly expanded the market size and business opportunities. Because SBDAs will provide a significant, global, real-time impact for on-site analysis and telemedicine opportunities, research developments are increasing in the area of cellphone-based devices for bioanalytical sciences, i.e., immunoassays, LFA, electrochemical sensing, and colorimetric detection (Figure 19) [70,111-122]. 

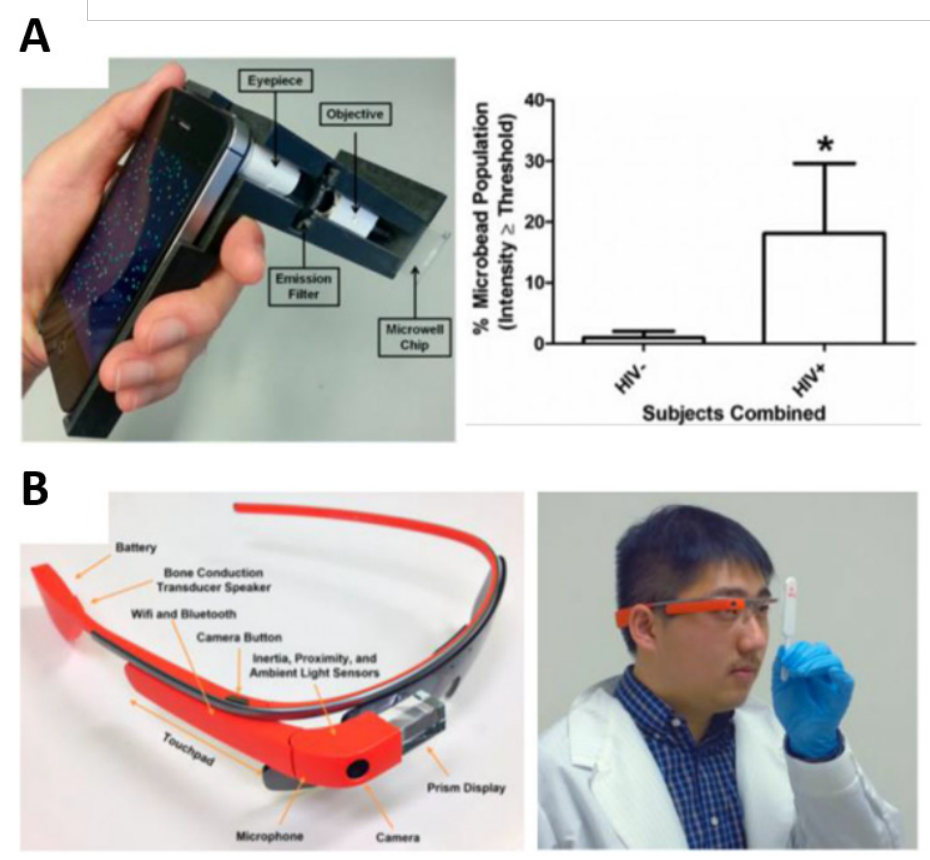

Figure 19. Smartphone based multiplex diagnostic platform using quantum dot barcodes facilitates simultaneous HIV, HBV, and HCV diagnostics in a single test. And RDT imaging and quantification using Google Glass.

A range of SBDA-based devices have been developed for colorimetric in vitro diagnostics. In the field of mHealthcare, it is important to note that SBDAs provide connectivity to remote healthcare laboratories, increased adherence to health monitoring, greater alignment to treatment and medication regimens, better management of chronic diseases, improved communication between healthcare professionals, community screening for specific disease conditions, and the prevention of infectious and sexually-transmitted diseases and child obesity [123-133]. Recent developments in mHealthcare and telemedicine have drawn much attention to the use of smartphones as a platform for various mobile healthcare applications. There has been a rapid growth in public interest for improved healthcare and better health management tools through various mHealthcare technologies.

The described commercial SBDAs are used by several million smartphone users worldwide. This has provided better healthcare monitoring and management and critically improved and sustainable health results. This movement will lead to significant cost-savings, as the users can participate in effective prevention and management if diseases including diabetes, obesity, coronary heart disease and even cancer. 
Healthcare can be revolutionized by pooling and examining vast data repositories via centralized cloud computing to establish enriched information for more predictive healthcare monitoring and management and save significant cost. The primary concern for this data collection is the security and privacy of personal data $[134,135]$. Similarly, there are concerns over the privacy of personal information data in personal health records (PHRs), as these could be exposed to the public. The ethical guidelines state that the patients should have full control over access to their own PHRs. Therefore, the strategies of attribute-based encryption and employing a trusted third party are being developed to address this concern $[136,137]$. Smartphone-based mobile cloud computing, which is being employed in the development of SBDAs, will provide the desired next generation of mHealthcare technology for personalized healthcare needs. In the next decade, we will likely witness a tremendous increase in healthcare-related smartphone features including an improved generation of mobile cloud computing and contributing technologies $[138,139]$. Among the emerging breakthrough technologies, foldable screens and three-dimensional tracking are likely to be integrated into smartphones. Additionally, smartphone costs will continue to come down as a result of the growing number of users and online-capable user accounts. Such positive developments will pave the way toward improved healthcare in developing countries.

\section{REFERENCES}

1. S.K. Vashist, O. Mudanyali, E.M. Schneider, R. Zengerle, A. Ozcan. Anal. Bioanal. Chem. 406 (2014) 3263-3277.

2. P.Y.K. Chau, P.J.-H. Hu. Inf. Manage. 39 (2002) 297-311.

3. GSMA, The mobile economy 2015, Available at: http://www.gsmamobileeconomy.com/GSMA_ Global_Mobile_Economy_Report_2015.pdf. (accessed: $7^{\text {th }}$ July 2016)

4. GSMA, The mobile economy 2016, Available at: https://gsmaintelligence.com/research/?file= 97928efe 09c dba2864cdcf1ad1a2f58c\&download. (accessed: $7^{\text {th }}$ July 2016)

5. The mobile economy India 2015, Available at: http://gsmamobileeconomy.com/india-new/. (accessed: 7th July 2016)

6. International Telecommunication Union, Market information and statistics, 2010. Available at: https://www.gsmaintelligence.com/research/?file=4113a57d43a9e93968e7e d00123ba4b2\&download. (accessed: $7^{\text {th }}$ July 2016)

7. World Health Organization, Telemedicine: opportunities and developments in member states, 2010. Available at: http://www.who.int/goe/publications/goe_telemedicine_2010.pdf. (Accessed: $7^{\text {th }}$ July 2016)

8. A. Roda, E. Michelini, M. Zangheri, M. Di Fusco, D. Calabria, P. Simoni. Trac. Trends Anal. Chem. 79 (2016) 317-325.

9. http://www.alivecor.com/en/. (Accessed: $8^{\text {th }}$ July 2016) 
10. http://www.forbes.com/sites/bernardmarr/2015/04/21/how-big-data-ischanging-healthcare/\#76d2b31632d9. (accessed: $8^{\text {th }}$ July 2016)

11. http://www.mobisante.com/products/product-overview/. (accessed: $8^{\text {th }}$ July 2016)

12. A. Ozcan. Lab Chip 14 (2014) 3187-3194.

13. WHO. A health telematics policy in support of WHO's Health-For-All strategy for global health development, 1998. Available at: http://apps.who.int/iris/bitstream/10665/63857/1/WHO_DGO_98.1.pdf. (accessed: $8^{\text {th }}$ July 2016)

14. J.C. Contreras-Naranjo, Q. Wei, A. Ozcan. IEEE J. Sel. Top. Quantum Electron. 22 (2016) 7100414.

15. A. Ozcan. Lab Chip 14 (2014) 3187-3194.

16. E. Petryayeva, W.R. Algar. RSC Adv. 5 (2015) 22256-22282.

17. Z. Gorocs, A. Ozcan. Lab Chip 14 (2014) 3248-3257.

18. H.Z. Yu, Y. Li, L.M.L. Ou. Acc. Chem. Res. 46 (2013) 258-268.

19. S. Morais, L. Tortajada-Genaro, A. Maquieira. Expert Rev. Mol. Diagn. 14 (2014) 773-775.

20. X. Xu A. Akay, H. Wei, S. Wang, B. Pingguan-Murphy, B.E. Erlandsson, X. Li, W. Lee, J. Hu, L. Wang, F. Xu. Proc. IEEE. 103 (2015) 236-247.

21. S.K. Vashist, O. Mudanyali, E.M. Schneider, R. Zengerle, A. Ozcan. Anal. Bioanal. Chem. 406 (2014) 3263-3277.

22. Z. Göröcs Y. Ling, M.D. Yu, D. Karahalios, K. Mogharabi, K. Lu, Q. Wei, A. Ozcan. Lab Chip 13 (2013) 4460-4466.

23. International Telecommunications Union, ICT facts and figures - The world in 2015. Available at:

http://www.itu.int/en/ITUD/Statistics/Pages/facts/default.aspx.

24. M.V. D’Ambrosio,M. Bakalar, S. Bennuru, C. Reber, A. Skandarajah, L. Nilsson, N. Switz, J. Kamgno, S. Pion, M. Boussinesq, T.B. Nutman, D.A. Fletcher. Sci. Transl. Med. 7 (2015) 286re4.

25. T. Laksanasopin, T.W. Guo, S. Nayak, A.A. Sridhara, S. Xie, O.O. Olowookere, P. Cadinu, F. Meng, N.H. Chee, J. Kim, C.D. Chin, E. Munyazesa, P. Mugwaneza, A.J. Rai, V. Mugisha, A.R. Castro, D. Steinmiller, V. Linder, J.E. Justman, S. Nsanzimana, S.K. Sia. Sci. Transl. Med. 7 (2015) 273re1.

26. H.C. Koydemir Z. Gorocs, D. Tseng, B. Cortazar, S. Feng, R.Y.L. Chan, J. Burbano, E. McLeod, A. Ozcan. Lab Chip 15 (2015) 1284-1293.

27. Q. Wei, W. Luo, S, Chiang, T. Kappel, C. Mejia, D. Tseng, R.Y.L Chan, E. Yan, H. Qi, F. Shabbir, H. Ozkan, S. Fengand, A. Ozcan. ACS Nano. 8 (2014) 12725-12733.

28. E. Petryayeva, W.R. Algar. RSC Adv. 5 (2015), 22256-22282.

29. D.N. Breslauer, R.N. Maamari, N.A. Switz, W.A. Lam, D.A. Fletcher. PLoS One 4 (2009) e6320.

30. A. Skandarajah, C.D. Reber, N.A. Switz, D.A. Fletcher. PLoS One 13 (2014) e96906.

31. R.K. Ephraim, E. Duah, J.S. Cybulski, M. Prakash, M.V. D'Ambrosio, D.A. Fletcher, J. Keiser, J.R. Andrews, I.I. Bogoch. Am. J. Trop. Med. Hyg. 92 (2015) 1253-1256.

32. D. Tseng, O. Mudanyali, C. Oztoprak, S.O. Isikman, I. Sencan, O. Yaglidere, A. Ozcan. Lab Chip 10 (2010) 1787-1792.

33. O. Mudanyali, D. Tseng, C. Oh, S.O. Isikman, I. Sencan, W. Bishara, C. Oztoprak, S. Seo, B. Khademhosseini, A. Ozcan. Lab Chip 7 (2010) 1417-1428. 
34. W. Bishara, U, Sikora, O, Mudanyali, T,-W, Su, O, Yaglidere, S, Luckhart, A. Ozcan. Lab Chip 11 (2011) 1276-1279.

35. A. Greenbaum, W. Luo, T.W. Su, Z. Göröcs, L. Xue, S.O. Isikman, A.F. Coskun, O. Mudanyali, A. Ozcan. Nat. Methods 9 (2012) 889-895.

36. A. Greenbaum, N. Akbari, A. Feizi, W. Luo, A. Ozcan. PLoS One 8 (2013) e76475.

37. E. McLeod, W. Luo, O. Mudanyali, A. Greenbaum, A. Ozcan. Lab Chip 13 (2013) 2028-2035.

38. A. Greenbaum, Y. Zhang, A. Feizi, P.-L. Chung, W. Luo, S.R. Kandukuri, A. Ozcan. Sci Transl. Med. 6 (2014) 267ra175.

39. I. Navruz A.F. Coskun, J. Wong, S. Mohammad, D. Tseng, R. Nagi, S. Phillips, A. Ozcan. Lab Chip 13 (2013) 4015-4023.

40. Z.J. Smith, K. Chu, A.R. Espenson, M. Rahimzadeh, A. Gryshuk, M. Molinaro, D.M. Dwyre, S. Lane, D. Matthews, S. Wachsmann-Hogiu. PLoS One 6 (2011) e17150.

41. I.I. Bogoch, J.R. Andrews, B. Speich, S.M. Ame, S.M. Ali, J. R.Stothard, J. Utzinger, J. Keiser. Am. J. Trop. Med. Hyg. 91 (2014) 1138-1141.

42. N.A. Switz, M.V. D'Ambrosio, D.A. Fletcher. PLoS One 9 (2014) e95330.

43. P. Preechaburana, A. Suska, D. Filippini. Sensors 12 (2012) 8586-8600.

44. Y.L. Sung, J. Jeang, C.H. Lee, W.C. Shih. J. Biomed. Opt. 20 (2015) 047005.

45. J.S. Cybulski, J. Clements, M. Prakash. PLoS One 9 (2014) e98781.

46. R.N. Maamari, J.D. Keenan, D.A. Fletcher, T.P. Margolis. Br. J. Ophthalmol. 98 (2014) 438-441.

47. R.N. Maamari, S. Ausayakhun, T.P. Margolis, D.A. Fletche, J.D. Keenan. JAMA Ophthalmol. 132 (2014) 894-895.

48. H. Zhu, O. Yaglidere, T.W. Su, D. Tseng, A. Ozcan. Lab Chip 11 (2011) 315-322.

49. J. Chang, P. Arbeláez, N. Switz, C. Reber, A. Tapley, J.L. Davis, A. Cattamanchi, D. Fletcher, J. Malik. Med Image Comput. Comput. Assist. Interv. 15 (2012) 345-352.

50. A. Tapley, N. Switz, C. Reber, J. L. Davis, C. Miller, J.B. Matovu, W. Worodria, L. Huang, D.A. Fletcher, A. Cattamanchi. J. Clin. Microbiol. 51 (2013) 1774-1778.

51. L.H. Chaisson, C. Reber, H. Phan, N. Switz, L.M. Nilsson, F. Myers, N.V. Nhung, L. Luu, T. Pham, C. Vu, H. Nguyen, A. Nguyen, T. Dinh, P. Nahid, D. Fletcher,

A. Cattamanchi . Int. J. Tuberc. Lung Dis. 19 (2015) 1068-1072.

52. K.K. Ghosh, L.D. Burns, E.D. Cocker, A. Nimmerjahn, Y. Ziv, A. El Gamal, M.J. Schnitzer. Nat. Methods. 8 (2011) 871-878.

53. G. Comina, A. Suska, D. Filippini. Biosens. Bioelectron. 77 (2016) 1153-1167.

54. J. Wu, L. Ouyang, N. Wadhawan, J. Li, M. Zhang, S. Liao, D. Levin, F. Lin. Biomed. Microdevices 16 (2014) 521-528.

55. K. Ming, J. Kim, M.J. Biondi, A. Syed, K. Chen, A. Lam, M. Ostrowski, A. Rebbapragada, J.J. Feldand, W.C.W. Chan. ACS Nano 9 (2015) 3060-3074.

56. S.D. Gan, K.R. Patel. J. Invest. Dermatol. 133 (2013) e12.

57. G.S. Sittampalam, N.P. Coussens, H. Nelson, M. Arkin, D. Auld, C. Austin, B. Bejcek, M. Glicksman, J. Inglese, P.W. Iversen, Z. Li, J. McGee, O. McManus, L. Minor, A. Napper, J.M. Peltier, T. Riss, O.J. Trask Jr., J. Weidner. J. Assay guidance manual.

58. C.M. McGeough, S. O'Driscoll. IEEE Trans. Biomed. Circuits Syst. 7 (2013) 655-659. 
59. S.K. Vashist, T. van Oordt, E.M. Schneider, R. Zengerle, F. von Stetten, J.H. Luong. Biosens. Bioelectron. 67 (2015) 248-255.

60. Y. Lu, W. Shi, J. Qin, B. Lin. Electrophoresis 30 (2009) 579-582.

61. S. Wang, X. Zhao, I. Khimji, R. Akbas, W. Qiu, D. Edwards, D.W. Cramer, B. Ye, U. Demirci. Lab Chip 11 (2011) 3411-3418.

62. A.I. Barbosa, P. Gehlot, K. Sidapra, A.D. Edwards, N.M. Reis. Biosens. Bioelectron. 70 (2015) 5-14.

63. H. Zhu, U. Sikora, A. Ozcan. Analyst 137 (2012) 2541-2544.

64. R. Lin, A. Sk arajah, R.E. Gerver, H.D. Neira, D.A. Fletcher, A.E. Herr. Lab Chip 15 (2015) 1488-1496.

65. P. LeDuc, M. Agaba, C.M. Cheng, J. Gracio, A. Guzman, A. Middelberg. Sci. Transl. Med. 6 (2014) 266fs48.

66. A. Chen, R. Wang, C.R. Bever, S. Xing, B.D. Hammock, T. Pan. Biomicrofluidics 8 (2014) 064101.

67. L.J. Macaulay, J.M. Bailey, E.D. Levin, H.M. Stapleton. Neurotoxicol. Teratol. 52 (2015) 119-126.

68. V. Gubala, L.F. Harris, A.J. Ricco, M.X. Tan, D.E. Williams. Anal. Chem. 84 (2012) 487-515 (2012).

69. P. Preechaburana, S. Macken, A. Suska, D. Filippini. Biosens. Bioelectron. 26 (2011) 2107-2013

70. D.J. You, T.S. Park, J.Y. Yoon. Biosens. Bioelectron. 40 (2013) 180-185.

71. X. Mao, T.J. Huang. Lab Chip 12 (2012) 1412-1416.

72. D.W. Inglis, N. Herman. Lab Chip 13 (2013) 1724-1731.

73. H. Zhu, U. Sikora, A. Ozcan. Analyst. 137 (2012) 2541-2544.

74. H. Zhu, S. Mavandadi, A.F. Coskun, O. Yaglidere, A. Ozcan. Anal. Chem. 83 (2011) 6641-6647.

75. H. Zhu, I. Sencan, J. Wong, S. Dimitrov, D. Tseng, K. Nagashima, A. Ozcan. Lab Chip 13 (2013) 1282-1288.

76. T.S. Park, W. Li, K.E. McCracken, J.-Y. Yoon. Lab Chip 13 (2013) 4832-4840.

77. T.S. Park, J.-Y. Yoon. IEEE Sens. J. 15 (2015) 1902-1907.

78. M.W. Kadlec, D. You, J.C. Liao, P.K. Wong. J. Lab. Autom. 19 (2014) 258-266.

79. D. Lee, W.P. Chou, S.H. Yeh, P.J. Chen, P.H. Chen. Biosens. Bioelectron. 26 (2011) 4349-4354.

80. D.A. Selck, M.A. Karymov, B. Sun, R.F. Ismagilov. Anal. Chem. 85 (2013) 11129-11136.

81. G. Zhang, C. Li, Y. Lu, H. Hu, G. Xiang, Z. Liang, P. Liao, P. Dai, W. Xing, J. Cheng. Biosens. Bioelectron. 26 (2011) 4708-4714.

82. Y.-W. Huang, V.M. Ugaz. Analyst. 138 (2013) 2522-2526.

83. B. Veigas, J.M. Jacob, M.N. Costa, D.S. Santos, M. Viveiros, J. Inácio, R. Martins, P. Barquinha, E. Fortunato, P.V. Baptista. Lab Chip 12 (2012) 4802-4808.

84. M. Mancuso, E. Cesarman, D. Erickson. Lab Chip 14 (2014) 3809-3816.

85. M.O. Noor, U.J. Krull. Anal. Chem. 86 (2014) 10331-10339.

86. B. Berg, B. Cortazar, D. Tseng, H. Ozkan, S. Feng, Q. Wei, R.YL. Chan, J. Burbano, Q. Farooqui, M. Lewinski, D. Di Carlo, O.B. Garnerand, A. Ozcan. ACS Nano. 9 (2015) 7857-7866.

87. A. Chen, R. Wang, C.R.S. Bever, S. Xing, B.D. Hammock, T. Pan. Biomicrofluidics. 8 (2014) 064101. 
88. P.A. Sandoz, A.F. Coskun, A. Chung, W.M. Weaver, O. Adeyiga, D. Khodadadi, A. Ozcan, D.Di Carlo. Proc. $16^{\text {th }}$ Int. Conf. Miniaturized Systems Chemistry Life Sci. (2012) 338-340.

89. O. Mudanyali, S. Dimitrov, U. Sikora, S. Padmanabhan, I. Navruz, A. Ozcan. Lab Chip 12 (2012) 2678-2686.

90. L.P.V. Cardoso, R.F. Dias, A.A. Freitas, E.M. Hungria, R.M. Oliveira, M. Collovati, S.G. Reed, M.S. Duthie, M.S.A. Martins. BMC Infect. Dis. 13 (2013) 497.

91. V. Oncescu, D. O’Dell, D. Erickson. Lab Chip 13 (2013) 3232-3238.

92. V. Oncescu, M. Mancuso, D. Erickson. Lab Chip 14 (2014) 759-763.

93. S. Lee, V. Oncescu, M. Mancuso, S. Mehta, D. Erickson. Lab Chip 14 (2014) 1437-1442.

94. A.W. Martinez, S.T. Phillips, E. Carrilho, S.W. Thomas, H. Sindi, G.M. Whitesides. Anal. Chem. 80 (2008) 3699-3707.

95. D. Gallegos, K.D. Long, H. Yu, P.P. Clark, Y. Lin, S. George, P. Nath, B.T. Cunningham. Lab Chip 13 (2013) 2124-2132.

96. A. García, M.M. Erenas, E.D. Marinetto, C.A. Abad, I. de Orbe-Paya, A.J. Palma, L.F. Capitán-Vallvey. Sens. Actuators B, Chem. 156 (2011) 350-359.

97. N. López-Ruiz, A. Martínez-Olmos, I.M. Pérez de Vargas-Sansalvador, M.D. Fernández-Ramos, M.A. Carvajal, L.F. Capitan-Vallvey, A.J. Palma. Sens. Actuators B, Chem. 171-172 (2012) 938-945.

98. A. Choodum, P. Kanatharana, W. Wongniramaikul, N.N. Daeid. Talanta. 115 (2013) 143-149.

99. M.O. Salles, G.N. Meloni, W.R. D. Araujo, T.R.L. C. Paixao. Anal. Methods. 6 (2014) 2047-2052.

100. C. Sicard, C. Glen, B. Aubie, D.Wallace, S. Jahanshahi-Anbuhi, K. Pennings, G.T. Daigger, R. Pelton, J.D. Brennana, C.D.M. Filipe . Water Res. 70 (2015) 360-369.

101. H.E. Kaoutit, P. Estevez, F.C. Garcia, F. Serna, J.M. Garcia. Anal. Methods. 5 (2013) 54-58.

102. S. Sumriddetchkajorn, K. Chaitavon, Y. Intaravanne. Sens. Actuators B, Chem. 191 (2014) 561-566.

103. N. Lopez-Ruiz, V.F. Curto, M.M. Erenas, F. Benito-Lopez, D. Diamond, A.J. Palma, L.F. Capitan-Vallvey. Anal. Chem. 86 (2014) 9554-9562.

104. A.F. Coskun, R. Nagi, K. Sadeghi, S. Phillips, A. Ozcan. Lab Chip 13 (2013) 4231-4238.

105. C.D. Chin, Y.K. Cheung, T. Laksanasopin, M.M. Modena, S.Y. Chin, A.A. Sridhara, D. Steinmiller, V. Linder, J. Mushingantahe, G. Umviligihozo, E. Karita, L. Mwambarangwe, S.L. Braunstein, J. van de Wijgert, R. Sahabo, J.E. Justman, W. El-Sadr, S.K. Sia. Clin. Chem. 59 (2013) 629-640.

106. V.F. Pamplona, E.B. Passos, J.Zizka, M.M. Oliveira, E. Lawson, E. Clua, R. Raskar. ACM Trans. Graph. $\mathbf{3 0}$ (2011) 1-8.

107. S. Feng, R. Caire, B. Cortazar, M. Turan, A. Wongand, A. Ozcan. ACS Nano. 8 (2014) 3069-3079.

108. A. Ozcan. Lab Chip 14 (2014) 3187-3194.

109. Measuring the Information Society Report by International Telecommunication Union. Available at: http://www.itu.int/dms_pub/itud/opb/ind/D-IND-ICTOI-2012-SUM-PDF-E.pdf (accessed on 22 $2^{\text {nd }}$ July 2014). 
110. Portfolio Research Mobile Factbook 2013. Available at: http://www.portioresearch.com/media/3986/Portio\%20Research\%20Mobil e\%20Factbook\%202013.pdf (accessed on 22nd July 2014).

111. S.K. Vashist, O. Mudanyali, E.M. Schneider, R. Zengerle, A. Ozcan. Anal. Bioanal. Chem. 406 (2014) 3263-3277.

112. Y. Lu, W. Shi, J. Qin, B. Lin. Electrophoresis. 30 (2009) 579-582.

113. A.F. Coskun, J. Wong, D. Khodadadi, R. Nagi, A. Tey, A. Ozcan. Lab Chip 13 (2013) 636-640.

114. H. Zhu, U. Sikora, A. Ozcan. Analyst. 137 (2012) 2541-2544.

115. NFC Immunoassays. Available at: http://gentag.com/environmentalgenomics/\#disposable. (accessed on 22nd July 2014).

116. C.M. McGeough, S. O’Driscoll. IEEE Trans. Biomed. Circ. Syst. 7 (2013) 655-659.

117. O. Mudanyali, S. Dimitrov, U. Sikora, S. Padmanabhan, I. Navruz, A. Ozcan. Lab Chip 12 (2012) 2678-2686.

118. Mobile Diagnostic Rapid Test Reader. Available at: http://mobileassay.com/products/mobile-assay-reader (accessed on 22 ${ }^{\text {nd }}$ July 2014).

119. D.C. Cooper, B. Callahan, P. Callahan, L. Burnett. Nat. Preced. (2012).

120. P.B. Lillehoj, M.C. Huang, N. Truong, C.M. Ho. Lab Chip 13 (2013) 2950-2955.

121. Wireless Smart Gluco-Monitoring System. Available at: http://www.ihealthlabs.com/glucometer/wireless-smart-gluco-monitoringsystem/ (accessed on 22 July 2014).

122. H. Zhu, I. Sencan, J. Wong, S. Dimitrov, D. Tseng, K. Nagashima, A. Ozcan. Lab Chip 13 (2013) 1282-1288.

123. P.Y. Benhamou, V. Melki, R. Boizel, F. Perreal, J.-L. Quesada, S. Bessieres-Lacombe, J.-L. Bosson, S. Halimi, H. Hanaire. Diabetes Metab. 33 (2007) 220-226.

124. P.M. Carrera, A.R. Dalton. Maturitas. 77 (2014) 37-40.

125. M.C. Carter, V.J. Burley, C. Nykjaer, J.E. Cade. J. Med. Internet Res. 15 (2013) e32.

126. M.B. Duffy. Gastrointest. Endosc. 79 (2014) 499-502.

127. S. Franc, S. Borot, O. Ronsin, J.-L. Quesada, D. Dardari, C. Fagour, E. Renard, A.-M. Leguerrier, C. Vigeral, F. Moreau, P. Winiszewski, A. Vambergue,

H. Mosnier-Pudar, L. Kessler, S. Reffet, B. Guerci, L. Millot, S. Halimi, C. Thivolet, P.-Y. Benhamou, A. Penfornis. Diabetes Metab. 40 (2014) 61-66.

128. C. Free, G. Phillips, L. Galli, L. Watson, L. Felix, P. Edwards, V. Patel, A. Haines. PLoS Med. 10 (2013) e1001362.

129. C. Free, al G. Phillips, L. Galli, L. Watson, L. Felix, P. Edwards, V. Patel, A. Haines. PLoS Med. 10 (2013) e1001363.

130. J. Joe, G. Demiris. J. Biomed. Inform. 46 (2013) 947-954.

131. R.M. Kaplan, A.A. Stone. Annu. Rev. Psychol. 64 (2013) 471-498.

132. G.A. O’Reilly, D. Spruijt-Metz. Am. J. Prev. Med. 45 (2013) 501-507.

133. J. Stephens, J. Allen. J. Cardiovasc. Nurs. 28 (2013) 320-329.

134. S, Subashini, V. Kavitha. J. Netw. Comput. Appl. 34 (2011) 1-11.

135. D.W. Sun, G.R. Chang, L.N. Sun, X.W. Wang. Procedia Eng. 15 (2011) 2852-2856.

136. D. Zissis, D. Lekkas. Future Gener. Comput. Syst. 28 (2012) 583-592.

137. M. Li, S.C. Yu, Y. Zheng, K. Ren, W.J. Lou. IEEE Trans. Parallel Distrib. 24 (2013) 131-143. 
138. H.T. Dinh, C. Lee, D. Niyato, P. Wang. Wirel. Commun. Mob. Comput. 13 (2013) 1587-1611.

139. M.N. Boulos, S. Wheeler, C. Tavares, R. Jones. Biomed. Eng. Online 10 (2011) 24. 